\title{
Mechanical Properties of T650-35/AFR-PE-4 at Elevated Temperatures for Lightweight Aeroshell Designs
}

\author{
Karen S. Whitley* and Timothy J. Collins ${ }^{\dagger}$ \\ NASA Langley Research Center, Hampton, VA 23681
}

\begin{abstract}
Considerable efforts have been underway to develop multidisciplinary technologies for aeroshell structures that will significantly increase the allowable working temperature for the aeroshell components, and enable the system to operate at higher temperatures while sustaining performance and durability. As part of these efforts, high temperature polymermatrix composites and fabrication technologies are being developed for the primary loadbearing structure (heat shield) of the spacecraft. New high-temperature resins and composite material manufacturing techniques are available that have the potential to significantly improve current aeroshell design. In order to qualify a polymer matrix composite (PMC) material as a candidate aeroshell structural material, its performance must be evaluated under realistic environments. Thus, verification testing of lightweight PMC's at aeroshell entry temperatures is needed to ensure that they will perform successfully in high-temperature environments. Towards this end, a test program was developed to characterize the mechanical properties of two candidate material systems, T650-35/AFR-PE-4 and T650-35/RP46. The two candidate high-temperature polyimide resins, AFR-PE-4 and RP46, were developed at the Air Force Research Laboratory and NASA Langley Research Center, respectively. This paper presents experimental methods, strength, and stiffness data of the T650-35/AFR-PE-4 material as a function of elevated temperatures. The properties determined during the research test program herein, included tensile strength, tensile stiffness, Poisson's ratio, compressive strength, compressive stiffness, shear modulus, and shear strength. Unidirectional laminates, a cross-ply laminate and two eight-harness satin (8HS)-weave laminates (4-ply and 10-ply) were tested according to ASTM standard methods at room and elevated temperatures $\left(23,316\right.$, and $\left.343^{\circ} \mathrm{C}\right)$. All of the relevant test methods and data reduction schemes are outlined along with mechanical data. These data contribute to a database of material properties for high-temperature polyimide composites that will be used to identify the material characteristics of potential candidate materials for aeroshell structure applications.
\end{abstract}

\section{Introduction}

NASA's In-Space Propulsion Technology Program ${ }^{1}$ is developing multiple technologies that will enable future robotic science and exploration missions. One of the goals of the program is to reduce mission cost for aerocapture systems. Aerocapture is an example of an aeroassist technology that uses a planet's atmospheric forces to decelerate a spacecraft during entry. The spacecraft is captured in its proper orbit in one pass through the atmosphere, without the use of on-board propulsion. Elimination of an on-board propulsion system saves mass, allowing a greater scientific payload to be delivered to the planet. Since weight-savings is directly related to mission cost, another technology needed includes lightweight structures for aeroshell designs.

An aeroshell system is a protective shell on a spacecraft that acts as a shielding surface and provides protection from the intense heating experienced during high-speed atmospheric entry. A typical aeroshell consists of three main parts including the external thermal protection material; adhesives used to bond the thermal protection system (TPS) to the aeroshell; and an underlying structure to which the spacecraft back-shell is attached, and the external thermal protection material is bonded. The aeroshell primary structure is typically fabricated from conventional composite materials. The amount of TPS, and thus the mass of the TPS layer, depends directly on the maximum

\footnotetext{
*Aerospace Engineer, Mechanics of Structures and Materials Branch, AIAA Member.

${ }^{\dagger}$ Aerospace Engineer, Mechanics of Structures and Materials Branch.
} 
allowable temperature for the primary structure and the adhesive bond that attaches the TPS material. Consequently, the use of advanced high-temperature composite materials and adhesives can significantly increase the allowable working temperature for the aeroshell structure, and in so doing produce a significant TPS mass savings for many mission scenarios.

In order to qualify a polymer matrix composite (PMC) material as a candidate aeroshell structural material, its performance must be evaluated under realistic environments. Thus, verification testing of lightweight PMC's at aeroshell entry temperatures is needed to ensure that they will perform successfully in high-temperature environments. Towards this end, a test program was developed that includes testing and characterization of two PMC's and several high-temperature adhesives ${ }^{2}$ whereas the objective of this paper focuses on the material property characterization of the T650-35/AFR-PE-4 composite material as a function of elevated temperatures. Towards this objective, a description of the T650-35/AFR-PE-4 composite material is presented first. Then the experimental methods and testing procedures that are used in the present study are discussed along with the results, which will include tensile modulus and strength, compressive modulus and strength, and interlaminar shear strength.

\section{Material Description}

The polymer matrix composite material, T650-35/AFR-PE-4 consists of a high-strength continuous carbon fiber (T650-35), and a high-temperature polyimide matrix (AFR-PE-4). The glass transition temperature ( $\mathrm{T}_{\mathrm{g}}$ ) of the resin material is $360^{\circ} \mathrm{C}$. Composite panels measuring 30.5 x $30.5 \mathrm{~cm}$ were fabricated by hand lay-up at the NASA Langley Research Center. These consisted of unidirectional, angle-ply, and 8HS-woven-fabric laminates.

The panels were vacuum bagged in a press and cured according to the process shown in figure 1 . A full vacuum was applied to the bagged panel during the entire cure cycle. The cycle started with a ramp to $240^{\circ} \mathrm{C}$ at $2.2^{\circ} \mathrm{C}$ /minute. After a 2-hour hold at $240^{\circ} \mathrm{C}$, the temperature was ramped to $280^{\circ} \mathrm{C}$ at $1.3^{\circ} \mathrm{C} / \mathrm{minute}$, and the temperature was held at $280^{\circ} \mathrm{C}$ for 1 hour. The temperature was then raised to $335^{\circ} \mathrm{C}$ at $1.3^{\circ} \mathrm{C} / \mathrm{minute}$, and $1379-\mathrm{kPa}$ (200-psi) pressure was applied. The temperature was held at $335^{\circ} \mathrm{C}$ for 2 hours, and was then raised to $371^{\circ} \mathrm{C}$ at $1.3^{\circ} \mathrm{C} /$ minute and held at $371^{\circ} \mathrm{F}$ for 2 hours. The pressure was released when the temperature reached $66^{\circ} \mathrm{C}$. The panels were then post-cured in air for 4 hours at $400^{\circ} \mathrm{C}$ and cooled to room temperature in 4 hours (the post-cure is not shown in figure 1). The panels were then cut into appropriate size test coupons for each ASTM standard.

\section{Material Property Characterization Methods and Results}

The complete test plan for this material is given in table 1 which includes the laminate configuration used for each ASTM standard test type, the experimental test temperatures, and the properties determined by each test.

\section{A. Tensile Modulus and Strength}

Tensile modulus of elasticity and ultimate tensile strength were determined from tension tests performed according to the ASTM standard D3039 ${ }^{3}$. Longitudinal strain $\left(\varepsilon_{\mathrm{x}}\right)$ in all test specimens was measured using an extensometer (MTS model 633.11E-15). Transverse strain $\left(\varepsilon_{\mathrm{y}}\right)$ was measured using electrical resistance strain gages bonded to the specimen. Measurements Group, Inc. strain gages CEA-06-250UW-350 were used for roomtemperature tests, and WK-06-250BG-350 gages were used for elevated-temperature tests. A schematic of the tensile specimens is given in figure 2, which also depicts the placement of the strain gages and extensometers. Specimens were mounted in a servo-hydraulic test machine with surfalloy wedge grips. Tests were performed using a constant displacement rate of $1.27 \mathrm{~mm} / \mathrm{min}$. Elevated temperature tests were performed in a forced-convectionheat oven mounted to the test stand. A type-K thermocouple positioned in close proximity to the specimen was used to monitor the temperature. When the temperature reached the desired set point, the specimen was soaked at that temperature for ten minutes prior to testing.

The lamina in-plane moduli values, $\mathrm{E}_{1}$ and $\mathrm{E}_{2}$ were calculated directly from the initial slope of the tangent to the initial linear portion of the stress-strain curve of $[0]_{8}$ and $[90]_{16}$ unidirectional laminates, respectively. In most cases, the linear region of the stress-strain curve was defined as being between $1000 \mu \varepsilon$ and $3000 \mu \varepsilon$ for all specimen layups and test temperatures. The laminate modulus value $\left(\mathrm{E}_{\mathrm{x}}\right)$ was calculated from the laminate stress-strain behavior of the 4-ply-fabric laminate. The lamina in-plane shear modulus $\left(\mathrm{G}_{12}\right)$ was calculated indirectly from the stressstrain behavior of $[ \pm 45]_{5 \mathrm{~s}}$ laminates subjected to axial loading according to the ASTM standard D3518 ${ }^{4}$ by using equation 1 where $E_{x}$ is the laminate longitudinal modulus (equation 2) and $v_{x y}$ is the laminate Poisson's ratio (equation 3). Longitudinal failure strength $\left(\sigma_{1}\right)$ and transverse failure strength $\left(\sigma_{2}\right)$ are defined as the maximum load divided by the nominal cross-sectional area of the $[0]_{8}$ and $[90]_{16}$ laminate specimens. 


$$
\begin{aligned}
& G_{12}=\frac{E_{x}}{2\left(1+v_{x y}\right)} \\
& E_{x}=\frac{\sigma_{x}}{\varepsilon_{x}} \\
& v_{x y}=-\frac{\varepsilon_{y}}{\varepsilon_{x}}
\end{aligned}
$$

The average tensile properties are listed in table 2. The stress versus strain curves (corresponding to table 2) from the $[0]_{8},[90]_{16},[ \pm 45]_{5 s}$, and the 4-ply-fabric laminate coupons are shown in figures $3-6$, respectively. For clarity in the figures $3-6$, only one representative curve is shown for each test temperature that represents the qualitative average for the number of replicates. The number of replicates at each test temperature is shown in parenthesis in the legend of the figure. For example, the blue curve in figure 3 represents the general data trend for the five replicates tested at room temperature.

It can be seen in figure 3 that temperature has little effect on the longitudinal modulus $\left(\mathrm{E}_{1}\right)$. The effects of elevated temperature on the transverse tensile $\left(\mathrm{E}_{2}\right)$ and shear moduli $\left(\mathrm{G}_{12}\right)$ were considerably stronger (figures 4 and 5). The average transverse tensile modulus $\left(\mathrm{E}_{2}\right)$ decreased from $7.80 \mathrm{GPa}$ at room temperature to $4.87 \mathrm{GPa}$ at $316^{\circ} \mathrm{C}$ $\left(600^{\circ} \mathrm{F}\right)$, which is a $37 \%$ reduction with respect to room temperature, and decreased further to $4.21 \mathrm{GPa}$ at $343^{\circ} \mathrm{C}$ $\left(650^{\circ} \mathrm{F}\right)$, resulting in a $46 \%$ reduction with respect to room temperature. The average shear modulus $\left(\mathrm{G}_{12}\right)$ decreased from $4.68 \mathrm{GPa}$ at room temperature to $2.14 \mathrm{GPa}$ at $316^{\circ} \mathrm{C}\left(600^{\circ} \mathrm{F}\right)$, a $54 \%$ reduction with respect to room temperature, and further decreased to $4.21 \mathrm{GPa}$ at $343^{\circ} \mathrm{C}\left(650^{\circ} \mathrm{F}\right)$, a $65 \%$ reduction with respect to room temperature. Elevated temperatures significantly reduced longitudinal $\left(\sigma_{1}\right)$ and transverse $\left(\sigma_{2}\right)$ tensile strengths. The transverse strength $\left(\sigma_{2}\right)$ was reduced by $41 \%$ at $316^{\circ} \mathrm{C}$, and $53 \%$ at $343^{\circ} \mathrm{C}$, with respect to room temperature. The longitudinal strength $\left(\sigma_{1}\right)$ was reduced approximately $20 \%$ at the elevated temperatures. Despite considerable scatter in the strength data of the 4-ply-fabric, the average values indicate relatively little change in strength, $\sigma_{\mathrm{x}}$, at the elevated temperatures compared to room temperature. Similarly, modulus $E_{x}$ of the 4-ply-fabric laminate also showed no significant effect due to temperature.

Regarding Poisson's ratio $\left(v_{12}\right)$, no clear evidence of an effect of temperature is observed. Therefore, it is assumed that $v_{12}$ is independent of temperature. The average value of $v_{12}$ is $0.32,0.31,0.32$ for room temperature, $316^{\circ} \mathrm{C}$, and $343^{\circ} \mathrm{C}$, respectively.

\section{B. Compressive Modulus and Strength}

The compressive modulus of elasticity and strength were determined by performing compression tests using the method described in the ASTM standard D695-96. The dog-bone shaped test specimen, depicted in figure 7, was mounted in a support fixture as shown in figure 8. This end-loaded compression fixture supported the specimen to prevent buckling, and allowed compression failure in the mid-section. The support fixture and the specimen were placed between upper and lower compression platens. The tests were performed in a servo-hydraulic test machine using a constant displacement rate of $1.27 \mathrm{~mm} / \mathrm{min}$. $(0.05 \mathrm{in} / \mathrm{min})$. Strain was measured using an extensometer mounted onto the exposed edge of the compression specimen. The compressive strength and modulus were calculated according to the method described in ASTM D695, by calculating the slope of the tangent to the initial linear portion of the stress-strain curve. The linear region of the stress-strain curve from the compression test was defined as being between $1000 \mu \varepsilon$ and $3000 \mu \varepsilon$ for all test conditions and specimen ply lay-ups. Failure was defined as the point when the specimen broke, resulting in a complete loss of load-carrying capability during the test.

The compressive properties at room temperature, $316^{\circ} \mathrm{C}$, and $343^{\circ} \mathrm{C}$ obtained from the dog-bone compression (DBC) tests are given in Table 3. The stress versus strain curves from the DBC tests are shown in figures $9-11$. As previously discussed in the tension section each curve in the figures $9-11$ is representative of the replicate tests that were performed at each test temperature.

It can be seen in figure 9 that the effect of temperature on the longitudinal compressive modulus at $316^{\circ} \mathrm{C}$ compared to room temperature is rather weak. There is a significant effect of temperature on the transverse compressive modulus as shown in figure 10 , which decreased from $8.3 \mathrm{GPa}$ at room temperature to $5.47 \mathrm{GPa}$ and $4.34 \mathrm{GPa}$ at $316^{\circ} \mathrm{C}$, and $343^{\circ} \mathrm{C}$, respectively. There was very little decrease in the compressive modulus of the 10 - 
ply-fabric, when going from room temperature to the elevated temperatures, especially considering that the decrease in modulus values were within the standard deviation. The longitudinal and 10-ply-fabric compressive strength decreased about $50 \%$ at the elevated temperatures. The lowest strength value occurred in the $[90]_{20}$ specimens. At room temperature, the longitudinal strength was $249 \mathrm{MPa}$. However, the $[90]_{20}$ specimens tested at $316^{\circ} \mathrm{C}$ and $343^{\circ} \mathrm{C}$ did not exhibit a failure mode, they simply compressed in the test fixture until there was no visible endloading remaining on the specimen, and the test was stopped.

\section{Interlaminar Shear Strength}

The interlaminar shear strengths were determined using the ASTM standard D3846 as a guide. The specimens were mounted in the same support fixture that was also used for the dog-bone-compression tests, and a compressive load is applied to a double-notched specimen as described in the standard. The notch depth was one-half the specimen thickness, $\mathrm{t}$, and the notch width was $1.27 \mathrm{~mm}$ (0.05 inches). A schematic of the specimen is shown in figure 12. This test was performed with a constant displacement rate of $1.27 \mathrm{~mm} / \mathrm{min}$. $(0.05 \mathrm{in} / \mathrm{min})$. The interlaminar shear strength was calculated by dividing the maximum shear load by the product of the specimen width and the length of the failed area between the two notches. The effect of elevated temperatures on the interlaminar shear strengths of the $[0]_{20},[90]_{20}$, and the 10-ply 8HS-fabric laminates is clearly demonstrated in figure 13. The results presented in figure 13 are also listed in table 4. The interlaminar shear strength decreased significantly as the temperature increased for all the laminates tested.

\section{Discussion}

The effect of elevated temperatures on the mechanical behavior of carbon/AFR-PE-4 needs to be thoroughly understood for the design of more advanced composite systems in structural applications such as lightweight aeroshell designs. The elastic properties of T650-35/AFRPE-4 were experimentally determined as a function of temperature using ASTM standard test methods. This was accomplished by performing tension, compression, and shear tests on [0], [90], $[ \pm 45]$, and $8 \mathrm{HS}-$ fabric composite materials at room temperature, $316^{\circ}$, and $343^{\circ} \mathrm{C}$.

It was found that the effect of elevated temperatures on the tensile and compressive moduli, $\mathrm{E}_{1}$ (obtained from [0]-ply laminates), and $\mathrm{E}_{\mathrm{x}}$ (obtained from 8HS-fabric laminates) was not major. However, the tensile and compressive transverse moduli were reduced by more than $30 \%$ at the elevated temperatures. The tensile strength, $\left(\sigma_{\mathrm{x}}\right)$ of the $8 \mathrm{HS}$-fabric laminates was not affected by temperature. The longitudinal tensile strengths $\sigma_{1}$, and $\sigma_{2}$, and the compressive strengths $\sigma_{1}, \sigma_{2}$, and $\sigma_{\mathrm{x}}$ were reduced at elevated temperatures. Interlaminar shear strength of T650-35/AFRPE-4 composite were measured by the double-notch shear test method between room temperature and $343^{\circ} \mathrm{C}$. Interlaminar shear strength decreased substantially with temperature for the laminates tested ([0], [90], 8HSfabric).

In general, as the temperature of the composite increased, the polymer matrix was more compliant, therefore the composite elastic stiffness constants decreased, especially the matrix-dominated constants (e.g. shear modulus, transverse Young's modulus). Another important factor associated with the effect of temperature on the mechanical behavior of T650-35/AFR-PE-4 composite system was the significant reduction in strength properties, especially

those dominated by the strength properties of the polymer matrix. There was a tendency toward lower shear and transverse tension strength values as the temperature was increased.

\section{Acknowledgements}

The authors wish to thank everyone who has contributed to this work. Clarence Stanfield for fabrication of the panels, Louis Simmons and Thomas Skalski for cutting the panels into test coupons, Stewart Walker, Doriann Muller, and Diane Griffin for testing the coupons. 


\section{References}

${ }^{1}$ Johnson, L., et al., "NASA In-Space Propulsion Technology Program: Overview and Update," NTRS: 2005-01-11; 20050000112, NASA Center for Aerospace Information, 2004.

${ }^{2}$ Collins, T.J., et al., "High Temperature Structures, Adhesives, and Advanced Thermal Protection Materials for Next Generation Aeroshell Design," 53rd Joint Army-NAVY-Air Force Propulsion Meeting, Monterey, CA, 2005.

${ }^{3}$ ASTM, "Standard Test Method for Tensile Properties of Polymer Matrix Composite Materials," D3039-95, American Society for Testing and Materials, 1995.

${ }^{4}$ ASTM, "Standard Practice for In-plane Sear Stress-Strain Response of Undirectional Reinforced Plastics," D3518-76, American Society for Testing and Materials, 1976.

${ }^{5}$ ASTM, "Standard Test Method for Compressive Properties of Rigid Plastics," D695-96, American Society for Testing and Materials, 1996.

${ }^{6}$ ASTM, "Standard Test Method for In-Plane Shear Strength of Reinforced Plastics," D3846-94, American Society for Testing and Materials, 1994.

Table 1. Test plan

\begin{tabular}{|l|l|l|}
\hline \multicolumn{1}{|c|}{$\begin{array}{c}\text { Test Type } \\
\text { ASTM Standard) }\end{array}$} & \multicolumn{1}{|c|}{ Laminate } & \multicolumn{1}{c|}{ Property } \\
\hline Tension (D3039) & {$[0]_{8}$} & $\begin{array}{l}\text { Longitudinal tensile modulus, } \mathrm{E}_{1} \\
\text { Longitudinal tensile strength, } \sigma_{1} \\
\text { Poisson's ratio, } v_{12}\end{array}$ \\
\hline Tension (D3039) & {$[90]_{16}$} & $\begin{array}{l}\text { Transverse tensile modulus, } \mathrm{E}_{2} \\
\text { Transverse tensile strength, } \sigma_{2}\end{array}$ \\
\hline Tension (D3039) & 4 -ply-fabric & $\begin{array}{l}\text { Tensile modulus } \mathrm{E}_{\mathrm{x}} \\
\text { Tensile strength, } \sigma_{\mathrm{x}}\end{array}$ \\
\hline Tension (D3518) & {$[ \pm 45]_{5 \mathrm{~s}}$} & In-plane shear modulus $\mathrm{G}_{12}$ \\
\hline Compression (D695) & {$[0]_{20}$} & $\begin{array}{l}\text { Longitudinal compressive modulus, } \mathrm{E}_{1} \\
\text { Longitudinal compressive strength, } \sigma_{1}\end{array}$ \\
\hline Compression (D695) & {$[90]_{20}$} & $\begin{array}{l}\text { Transverse compressive modulus, } \mathrm{E}_{2} \\
\text { Transverse compressive strength, } \sigma_{2}\end{array}$ \\
\hline Compression (D695) & 10 -ply-fabric & $\begin{array}{l}\text { Compressive modulus } \mathrm{E}_{\mathrm{x}} \\
\text { Compressive strength, } \sigma_{\mathrm{x}}\end{array}$ \\
\hline Shear strength (D3846) & {$[0]_{20}$} & Interlaminar shear strength \\
\hline Shear strength (D3846) & {$[90]_{20}$} & Interlaminar shear strength \\
\hline Shear strength (D3846) & $10-$ ply-fabric & Interlaminar shear strength \\
\hline
\end{tabular}

Note 1. Test temperatures include 23,316 , and $343^{\circ} \mathrm{C}$ for each test type.

Note 2. All fabric laminates are 8HS-weave material. 
Table 2. Measured tensile properties with standard deviation

\begin{tabular}{|c|c|c|c|}
\hline \multirow{2}{*}{ Tensile Property } & \multicolumn{3}{|c|}{ Test Temperature } \\
\cline { 2 - 4 } & $2^{\circ} \mathbf{C}$ & $\mathbf{3 1 6}^{\circ} \mathbf{C}$ & $\mathbf{3 4 3}^{\circ} \mathbf{C}$ \\
\hline $\mathrm{E}_{1}(\mathrm{GPa})$ & $117 \pm 6$ & $116 \pm 6$ & $115 \pm 13$ \\
\hline $\mathrm{E}_{2}(\mathrm{GPa})$ & $7.80 \pm 0.58$ & $4.87 \pm 0.22$ & $4.21 \pm 0.07$ \\
\hline$\sigma_{1}(\mathrm{MPa})$ & $1445 \pm 197$ & $1177 \pm 219$ & $1132 \pm 219$ \\
\hline$\sigma_{2}(\mathrm{MPa})$ & $66 \pm 19$ & $39 \pm 3$ & $31 \pm 2$ \\
\hline$v_{12}$ & $0.32 \pm 0.02$ & $0.31 \pm 0.05$ & $0.32 \pm 0.06$ \\
\hline $\mathrm{G}_{12}(\mathrm{GPa})$ & $4.68 \pm 0.46$ & $2.14 \pm 0.07$ & $1.65 \pm 0.18$ \\
\hline $\mathrm{E}_{\mathrm{x}}(\mathrm{GPa})^{*}$ & $77 \pm 1$ & $76 \pm 1$ & $81 \pm 1$ \\
\hline$\sigma_{\mathrm{x}}(\mathrm{MPa})^{*}$ & $832 \pm 21$ & $830 \pm 45$ & $835 \pm 48$ \\
\hline
\end{tabular}

* 4-ply-fabric laminate

Table 3. Measured compressive properties with standard deviation

\begin{tabular}{|l|c|c|c|}
\hline \multirow{2}{*}{$\begin{array}{l}\text { Compressive } \\
\text { Property }\end{array}$} & \multicolumn{3}{|c|}{ Test Temperature } \\
\cline { 2 - 4 } & $\mathbf{2 3}^{\circ} \mathbf{C}$ & $\mathbf{3 1 6}^{\circ} \mathbf{C}$ & $\mathbf{3 4 3}^{\circ} \mathbf{C}$ \\
\hline $\mathrm{E}_{1}(\mathrm{GPa})$ & $111 \pm 3$ & $106 \pm 7$ & $112 \pm 6$ \\
\hline $\mathrm{E}_{2}(\mathrm{GPa})$ & $8.30 \pm 0.18$ & $5.47 \pm 0.37$ & $4.34 \pm 0.35$ \\
\hline$\sigma_{1}(\mathrm{MPa})$ & $865 \pm 56$ & $392 \pm 70$ & $375 \pm 88$ \\
\hline$\sigma_{2}(\mathrm{MPa})$ & $249 \pm 11$ & $\S$ & $\S$ \\
\hline $\mathrm{E}_{\mathrm{x}}(\mathrm{GPa})^{*}$ & $67 \pm 4$ & $65 \pm 4$ & $63 \pm 4$ \\
\hline$\sigma_{\mathrm{x}}(\mathrm{MPa})^{*}$ & $519 \pm 68$ & $280 \pm 10$ & $220 \pm 31$ \\
\hline
\end{tabular}

$\S$ Specimens did not fail

* 10-ply-fabric laminate

Table 4. Measured interlaminar shear strength (MPa) with standard deviation

\begin{tabular}{|l|c|c|c|}
\hline \multirow{2}{*}{$\begin{array}{l}\text { Laminate } \\
\text { Lay-up }\end{array}$} & \multicolumn{3}{|c|}{ Test Temperature } \\
\cline { 2 - 4 } & $\mathbf{2 3}^{\circ} \mathbf{C}$ & $\mathbf{3 1 6}^{\circ} \mathbf{C}$ & $\mathbf{3 4 3}^{\circ} \mathbf{C}$ \\
\hline$[0]_{20}$ & $73 \pm 8$ & $41 \pm 8$ & $31 \pm 2$ \\
\hline$[90]_{20}$ & $47 \pm 11$ & $29 \pm 3$ & $24 \pm 1$ \\
\hline 10 -ply-fabric & $32 \pm 5$ & $19 \pm 3$ & $12 \pm 2$ \\
\hline
\end{tabular}




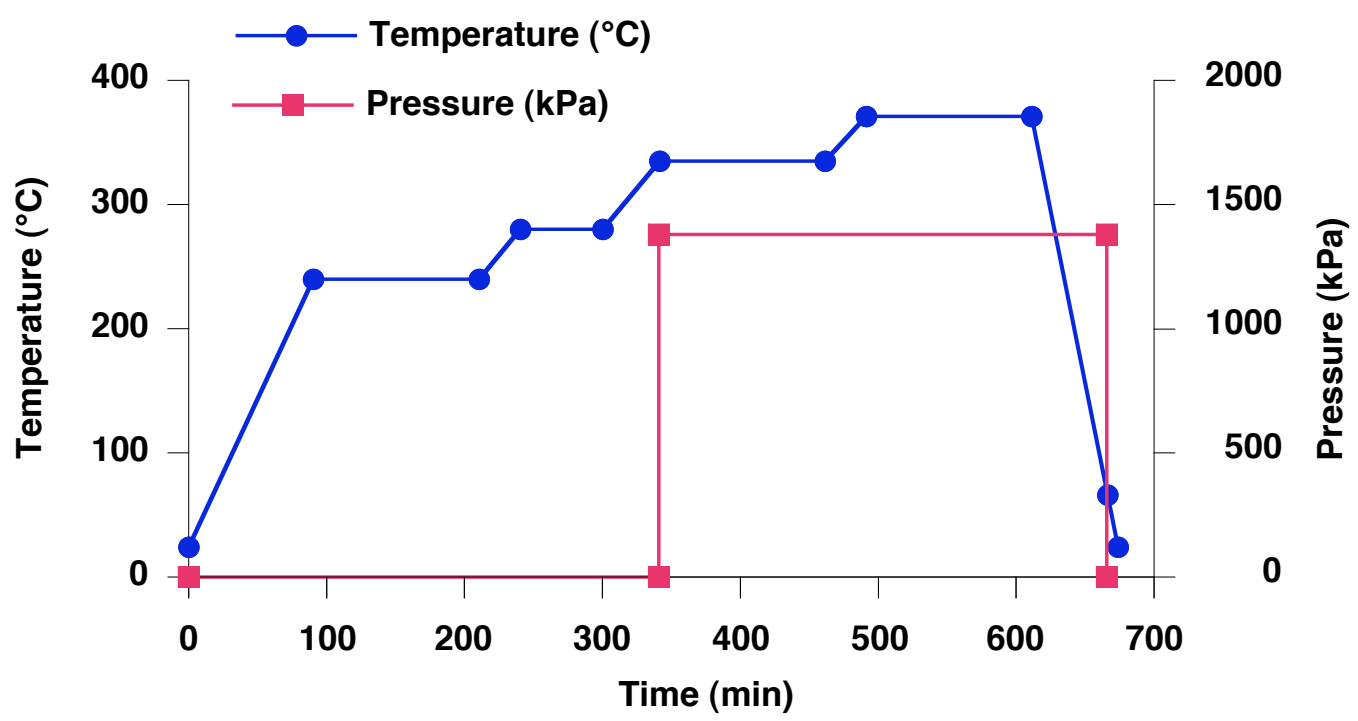

Figure 1. Cure cycle.

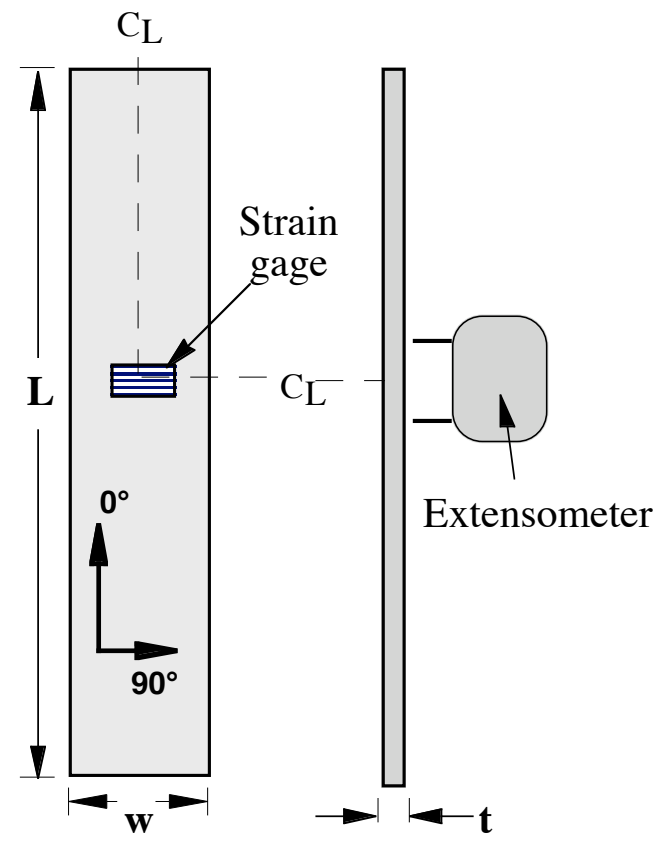

\begin{tabular}{|lll|}
\hline Specimen & $\mathbf{w}(\mathbf{m m})$ & $\mathbf{L}(\mathbf{m m})$ \\
{$[0]_{8}$} & 12.7 & 254.0 \\
{$[90]_{16}$} & 25.4 & 177.8 \\
{$\left[{ }^{4} 45\right]_{5 \mathrm{~s}}$} & 25.4 & 254.0 \\
4-ply fabric & 12.7 & 254.0 \\
\hline
\end{tabular}

Figure 2. Schematic drawing of tensile specimens. 


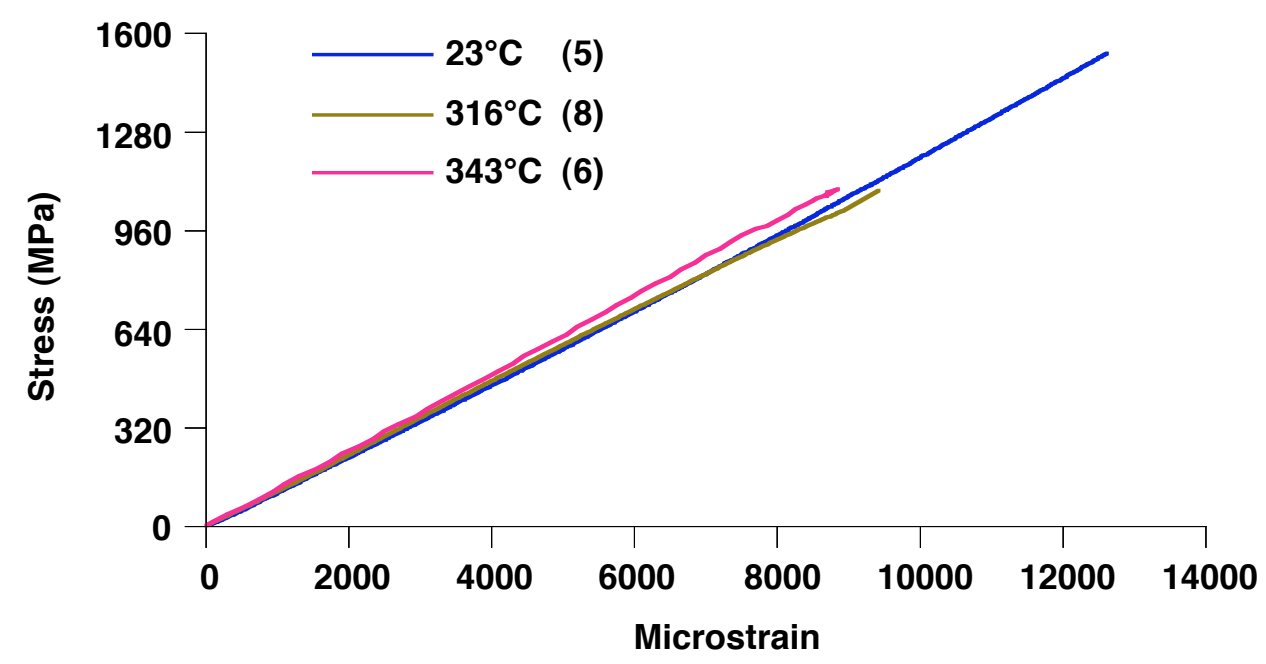

Figure 3. Tensile stress vs. strain curves for tension $[0]_{8}$ specimens.

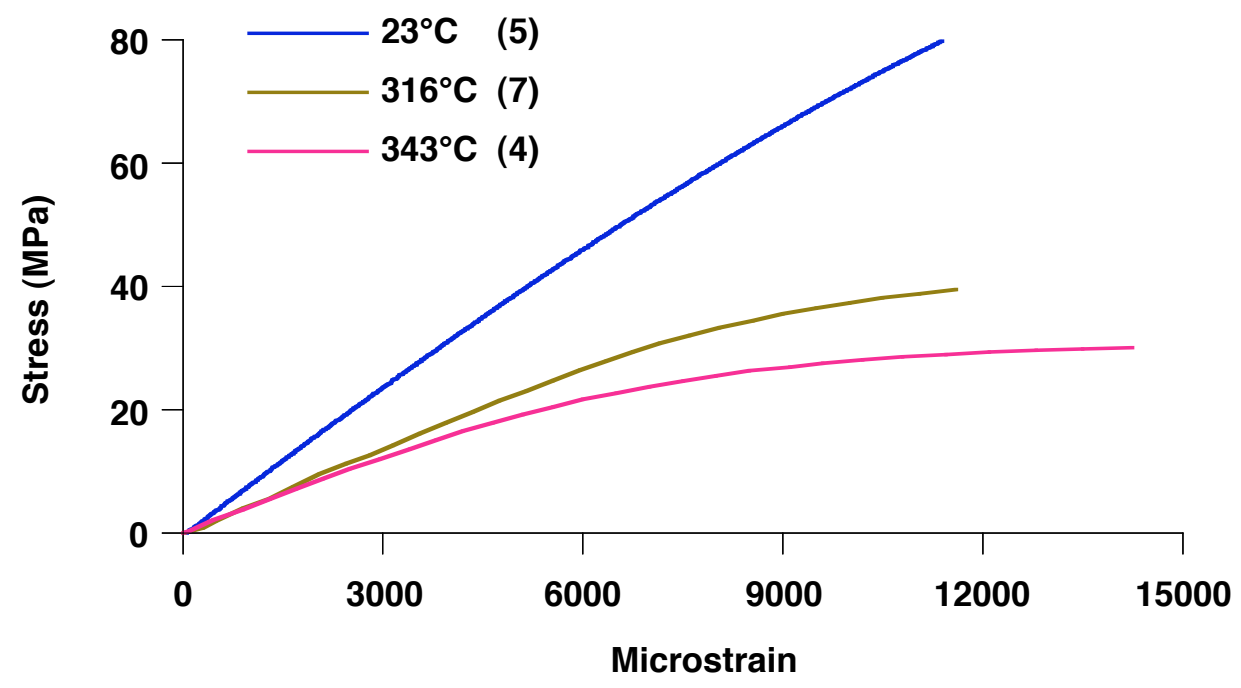

Figure 4. Tensile stress vs. strain curves for $[90]_{16}$ specimens. 


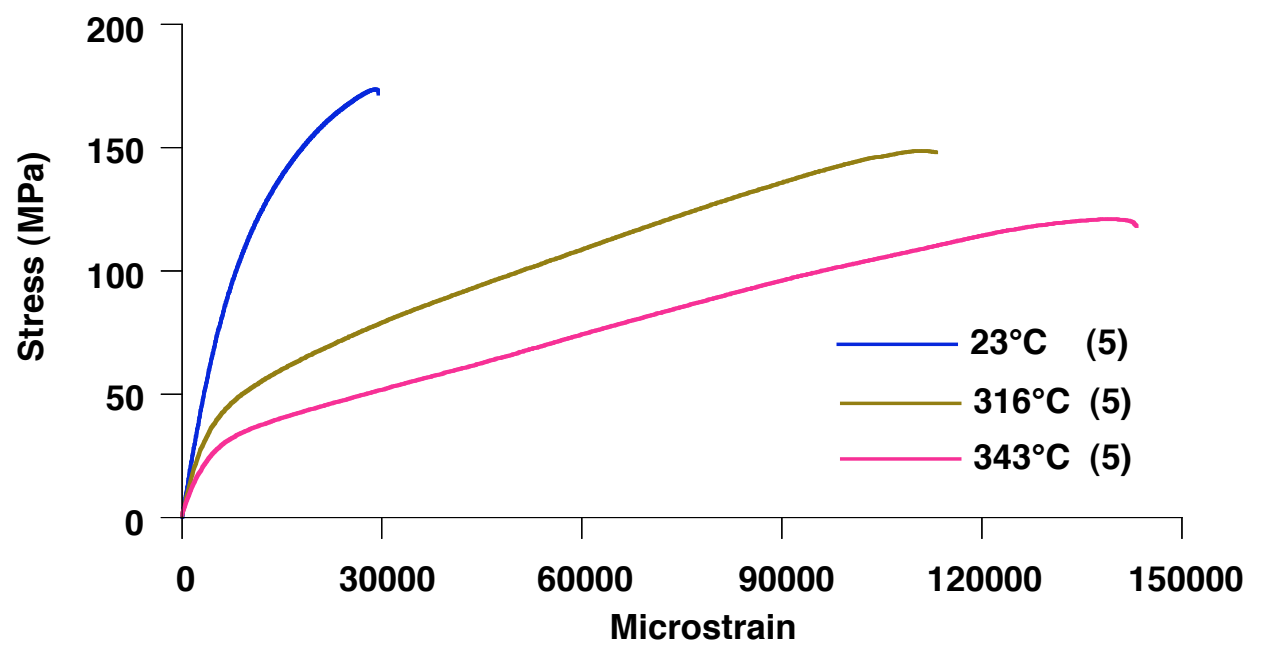

Figure 5. Tensile stress vs. strain curves for $[ \pm 45]_{5 s}$ specimens.

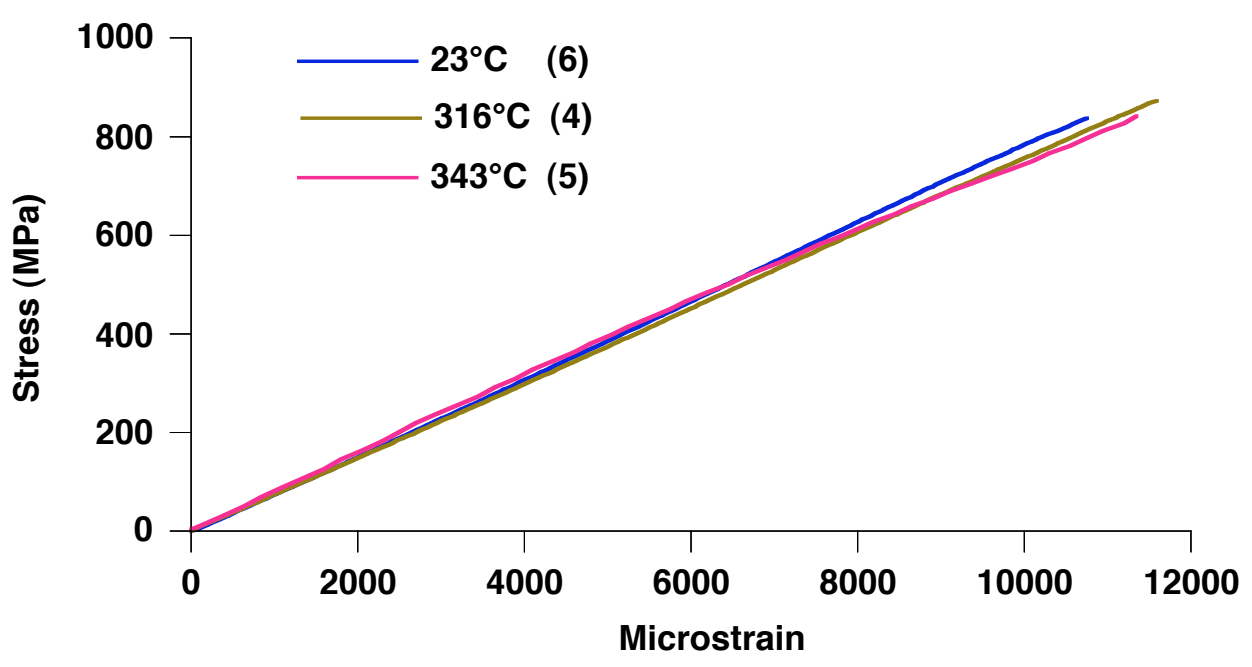

Figure 6. Tensile stress vs. strain curves for 4-ply fabric laminate specimens. 


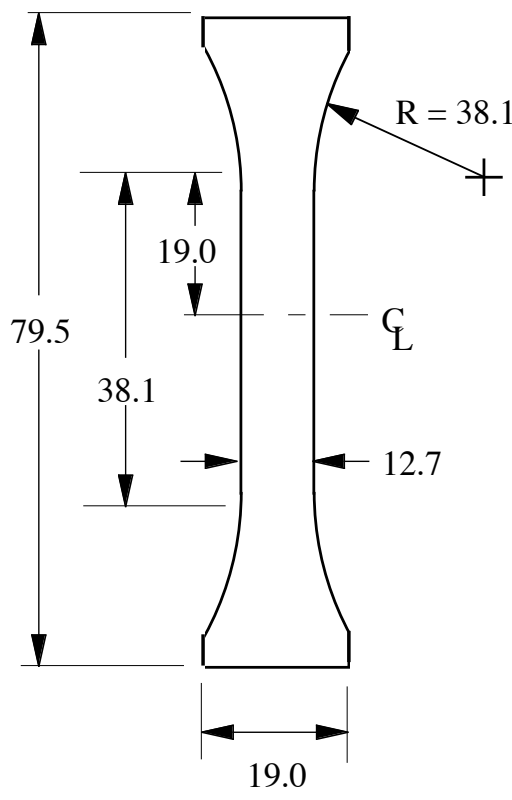

Dimensions are in $\mathrm{mm}$.

Figure 7. Diagram of dog-bone shaped compression specimen for ASTM D695-96 tests.

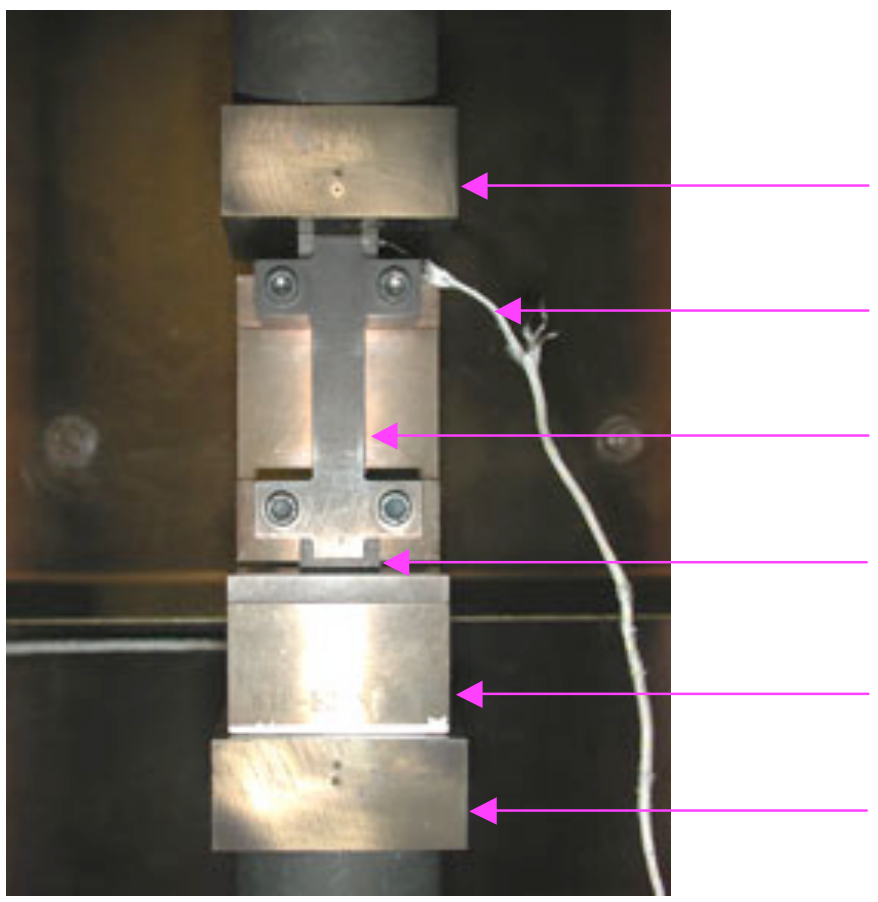

Test stand upper-compression-platen

Thermocouple

Anti-buckling guide

Dog-bone compression specimen

Support fixture

Test stand lower-compression-platen

Figure 8. Picture of DBC specimen mounted in support fixture and positioned in test stand. This support fixture is also used in the interlaminar shear tests. 


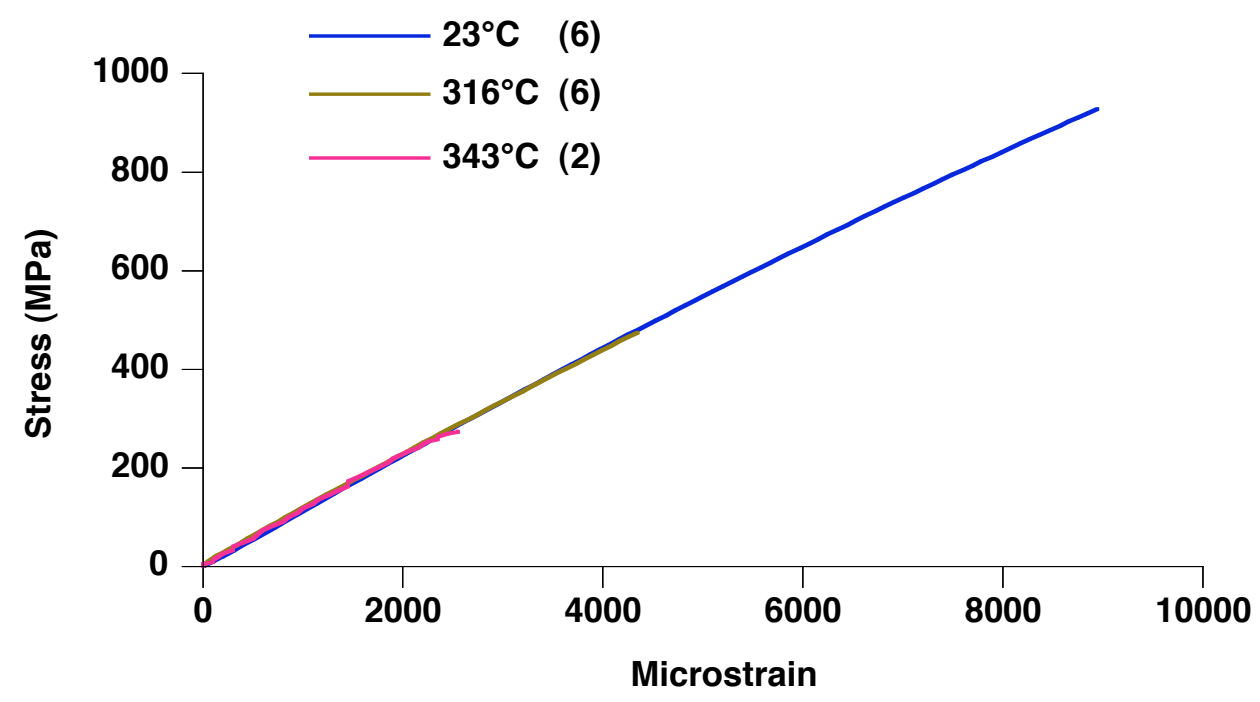

Figure 9. Dog-bone compression stress vs. strain for $[0]_{20}$.

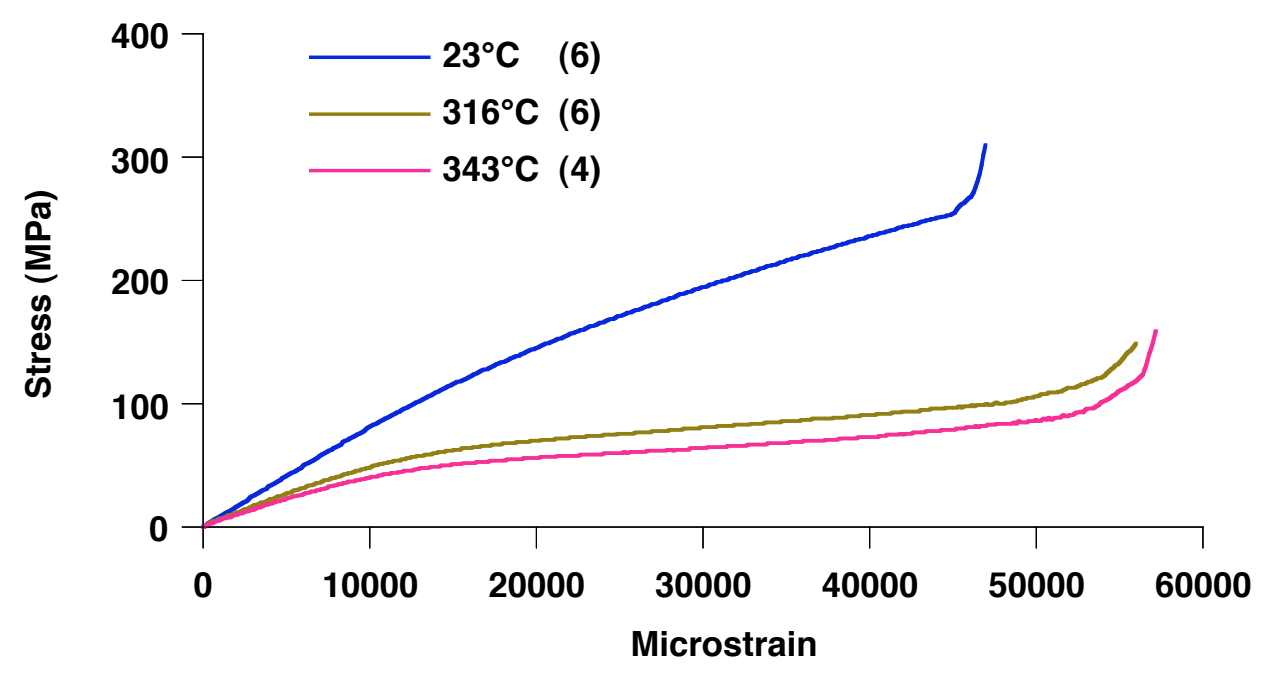

Figure 10. Dog-bone compression stress vs. strain for $[90]_{20}$. 


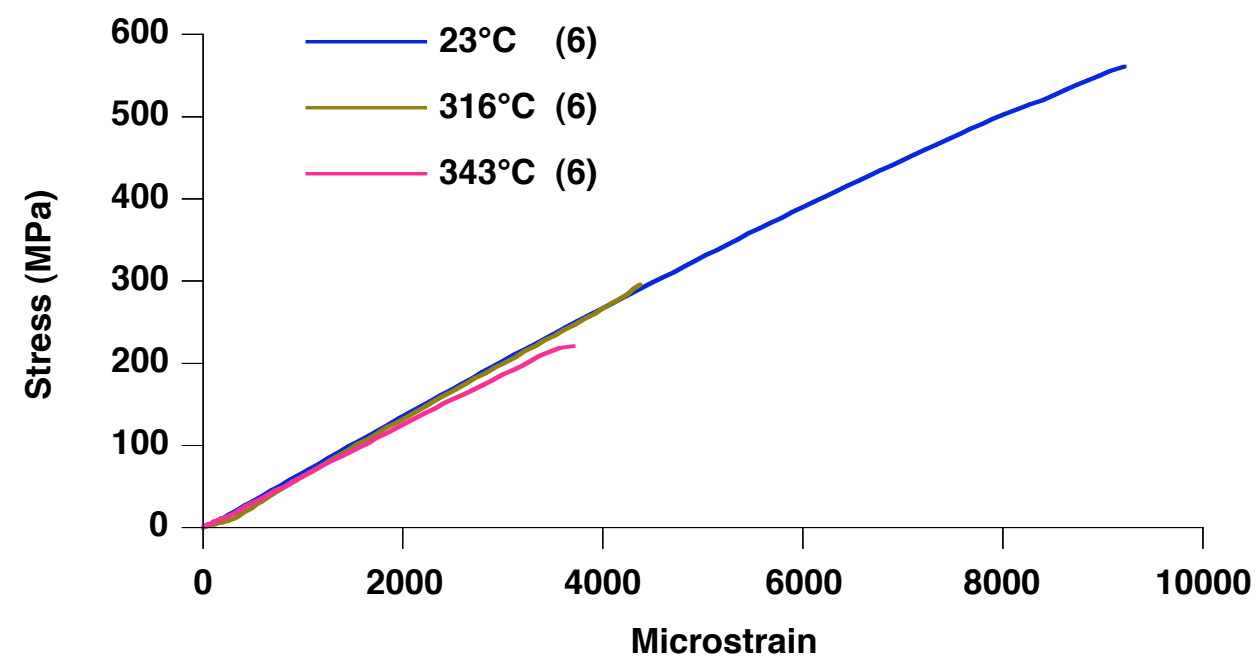

Figure 11. Dog-bone compression stress vs. strain for 10-ply fabric laminate.

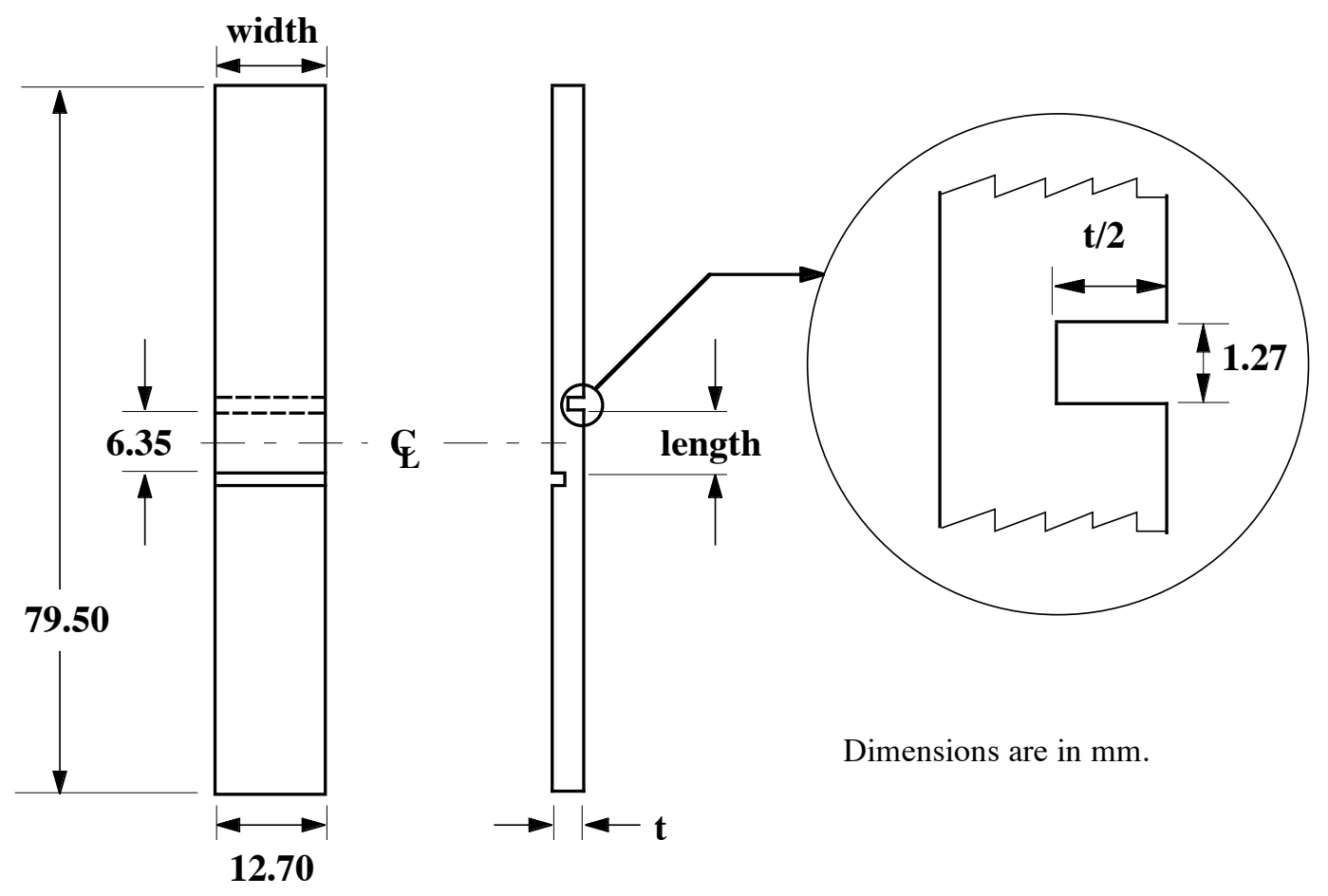

Figure 12. Diagram of the interlaminar shear test specimen from ASTM D3846. 


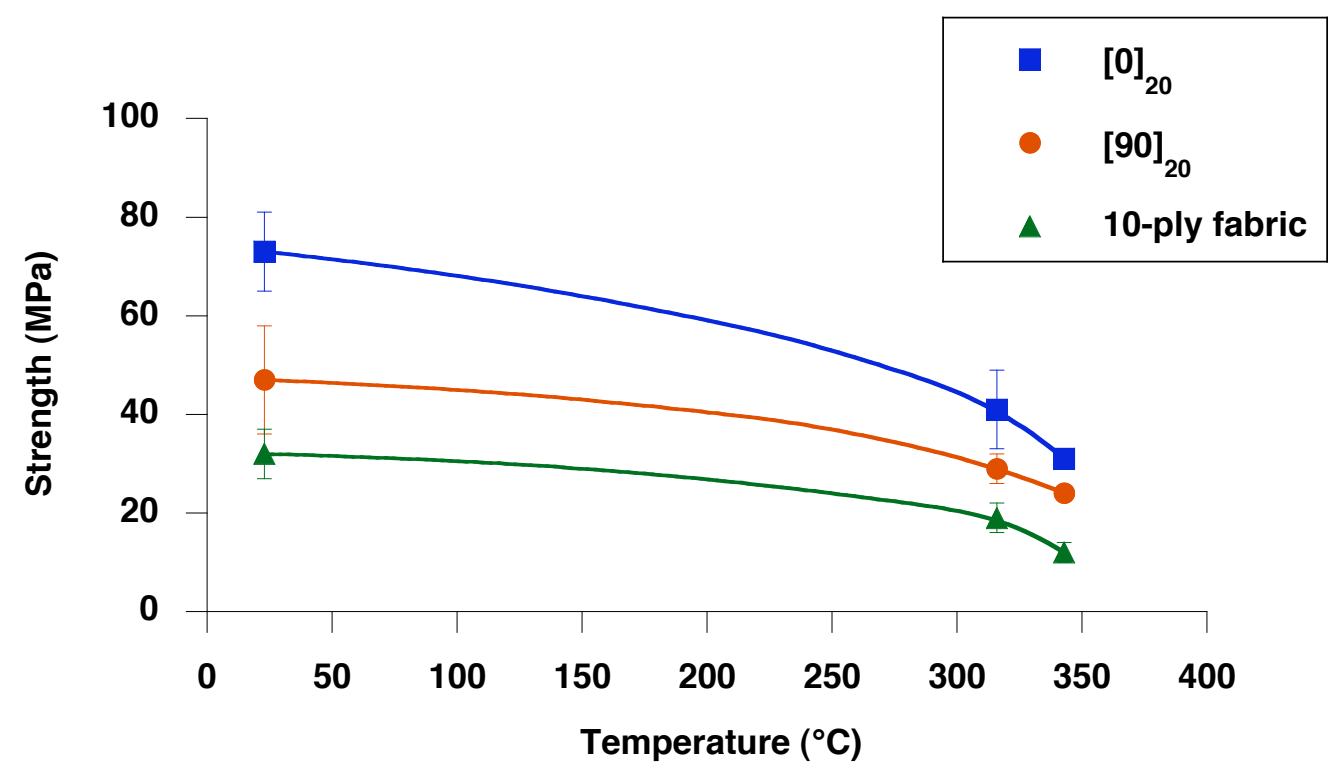

Figure 13. Interlaminar shear strength from ASTM D-3846 tests. 